\title{
Properties of Multimode Optical Epoxy Polymer Waveguides Deposited on Silicon and TOPAS Substrate
}

\author{
Vaclav PRAJZLER ${ }^{1}$, Milos NERUDA ${ }^{1}$, Pavla NEKVINDOVA ${ }^{2}$, Petr MIKULIK ${ }^{3}$ \\ ${ }^{1}$ Dept. of Microelectronics, Faculty of Electrical Engineering, Czech Technical University, \\ Technická 2, 16627 Prague, Czech Republic \\ ${ }^{2}$ Institute of Chemical Technology, Technická 5, 16627 Prague, Czech Republic \\ ${ }^{3}$ Dept. of Condensed Matter Physics, Masaryk University, Kotlárska 2, 61137 Brno, Czech Republic
}

xprajzlv@feld.cvut.cz

Submitted May 25, 2016 / Accepted November 11, 2016

\begin{abstract}
The paper reports on the fabrication and characterization of multimode polymer optical waveguides. Epoxy polymer EpoCore was used as the waveguide core material and EpoClad was used as a cladding and cover protection layer. The design of the waveguides was schemed for geometric dimensions of $50 \mu \mathrm{m}$ core and for $850 \mathrm{~nm}$ and $1310 \mathrm{~nm}$ wavelengths. Proposed shapes of the waveguides were fabricated by standard photolithography process. Optical losses of the planar waveguides were measured by the fibre probe technique at $632.8 \mathrm{~nm}$ and $964 \mathrm{~nm}$. Propagation optical loss measurements for rectangular waveguides were done by using the cut-back method and the best samples had optical losses lower than $0.53 \mathrm{~dB} / \mathrm{cm}$ at $650 \mathrm{~nm}, 850 \mathrm{~nm}$ and $1310 \mathrm{~nm}$.
\end{abstract}

\section{Keywords}

Optical planar waveguides, optical rectangular waveguides, multimode waveguides, polymer

\section{Introduction}

Optical data transmission has become the obvious choice for communication over longer distances, but copper based electrical interconnects have dominated shortrange communication links for over decades. The increasing demand in recent years for interconnection bandwidth in data centers and supercomputers, in conjunction with the inherent disadvantages of copper interconnects when operating at high data rates $(>10 \mathrm{~Gb} / \mathrm{s})$, has led to the consideration of the use of optical technologies in very short communication links [1-3]. This new trends force designers to use optical interconnections also to bridge short distances including optical communications like Short Reach (SR) up to $300 \mathrm{~m}$, Extra Short Reach (ESR) up to $5 \mathrm{~cm}$ and also Ultra Short Reach (USR) or even $1 \mathrm{~cm}$. For such new optical communications systems, it is highly desirable to develop new technology techniques with new optical materi- als, which will allow high operating data rates and would make fabrication process simple and cheap.

The key waveguide components for formation of such complex on-board optical layouts include multimode ridge waveguides. Therefore, many research groups are looking for fabrication of suitable elements that would combine new materials having comparable properties and the same time a possibility to be prepared by easy fabrication process in order to make production of those structures possible in a large scale, low cost and also environmentally friendly.

Multimode polymer waveguides are a particularly attractive option for the ESR and USR communications because they exhibit favorable optical, mechanical and thermal properties allowing their direct integration onto low cost printed circuit boards with standard methods of conventional electronics manufacturing. Optical interconnects via polymer waveguides have attracted considerable attention during the last decade also because they enable fabrication of multimode optical waveguide structures on printed circuit boards [4-8] and flexible foil substrate using low-cost assembly and packaging methods [9], [10].

This paper presents a new approach to realize multimode polymer ridge waveguides for optical interconnection applications. In developing the new approach, epoxy polymer was selected as a core waveguide material while EpoClad polymer material was selected for cladding; both supported by Micro resist technology GmbH. These materials possess excellent properties such as high heat and pressure resistance, low optical losses $\left(<0.49 \mathrm{~dB} \cdot \mathrm{cm}^{-1}\right.$ at $633 \mathrm{~nm}[11,12], 0.2 \mathrm{~dB} \cdot \mathrm{cm}^{-1}$ at $850 \mathrm{~nm}$, refractive index EpoCore 1.58, EpoClad 1.57, $\lambda=830 \mathrm{~nm}$ [13]), easy fabrication process, etc. For the substrate we used silicon and flexible TOPAS polymer foil 8007X4. TOPAS is Cyclic Olefin Copolymer and it is a glass-clear amorphous polymer with outstanding moisture barrier, chemical resistance, high purity and non-reactive surface making it an excellent choice for optical interconnections [14]. 


\section{Design of Planar and Ridge Waveguides}

To design and develop an optical rib waveguide one usually needs to start with a slab waveguide. The slab waveguide is a planar dielectric thin film (core) with refractive index $n_{\mathrm{f}}$ which is sandwiched between a substrate and cover (or superstrate, or cladding) with lower refractive indices $n_{\mathrm{s}}$ and $n_{\mathrm{c}}$, respectively (see Fig. 1a).

The guiding mechanism is provided by total reflections along the vertical dimension. In the simplest case the core is deposited on the same substrate as a cover layer; than the slab is called symmetric $\left(n_{\mathrm{s}}=n_{\mathrm{c}}\right)$. The ridge waveguides are ones of the most commonly used optical waveguides in integrated optics and photonics. They have shape of a rectangular as shown in Fig. $1 b$; in our case we used cladding and cover layer made of the same polymer materials (EpoClad) and therefore it may be called a symmetric waveguide.

Suitability of the polymer EpoCore and EpoClad materials proposed for the cores and cladding of the planar waveguides was checked by Spectrometer Shimadzu (UV3600). The measurements showed that the materials were transparent within the range from 400 to $1600 \mathrm{~nm}$ (see Fig. 2) and therefore fulfill the requirements for their suitability stated above.

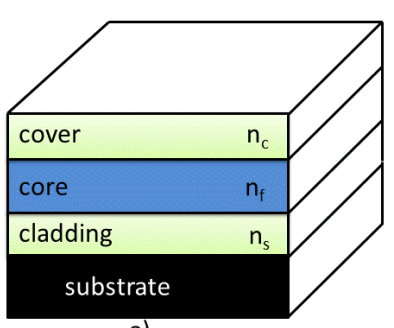

a)

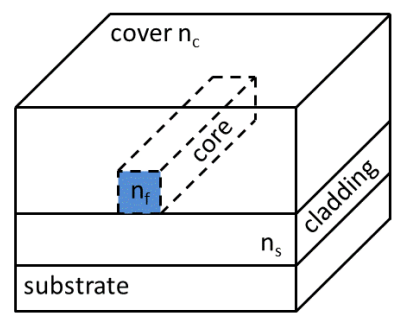

b)
Fig. 1. Cross-sectional view: a) optical planar waveguide, b) ridge waveguide.

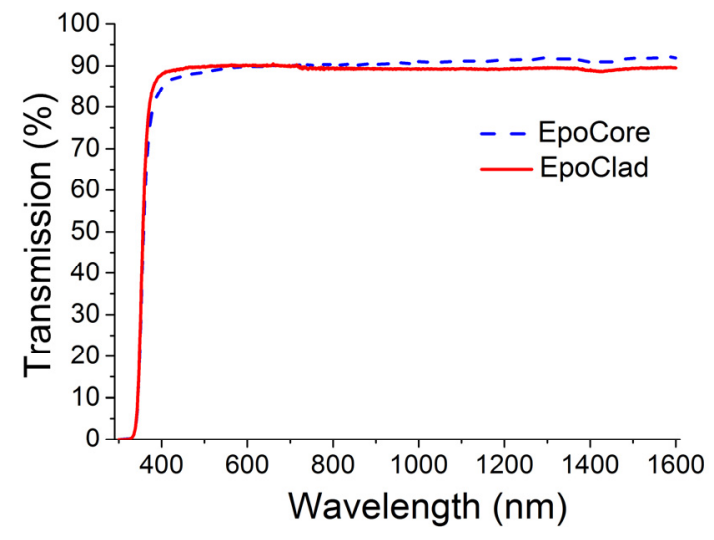

Fig. 2. Transmission spectra of EpoClad and EpoCore polymers.

\section{Fabrication}

The waveguides were prepared using epoxy negative tone photoresists EpoCore (core layer) and EpoClad polymer (cladding and cover layers) supplied by Micro resist technology $\mathrm{GmbH}$. The waveguiding layers were deposited onto silicon and flexible TOPAS 8007X4 (thickness 0.125 and $0.3 \mathrm{~mm}$ ) substrates.

The optimized fabrication process of the samples is illustrated step by step in Fig. 3 a-f and consisted of the following steps:

- Cleaning by plasma etching (Fig. 3a).

- Deposition of the EpoClad layers by spin coating (Fig. 3b) followed by soft bake process done for 10 minutes on a hot plate at $50^{\circ} \mathrm{C}$ after which the temperature was gradually increased to $90^{\circ} \mathrm{C}$ (at $10^{\circ} \mathrm{C} / \mathrm{min}$ ). Finally, a UV-curing process was applied followed by a bake process. This bake process was the same as before the UV curing.

- Deposition of an EpoCore layer on it by spin coating (Fig. 3c) and again, the soft-bake process was applied on a hotplate at $50^{\circ} \mathrm{C}$ for $10 \mathrm{~min}$. Afterwards, the temperature was once again gradually increased to $90^{\circ} \mathrm{C}$ (at $10^{\circ} \mathrm{C} / \mathrm{min}$ ).

- Photolithography process using PERKIN-ELMER 300 HT Micralign was performed (Fig. 3d). Then again bake process was applied at $50^{\circ} \mathrm{C}$ for $10 \mathrm{~min}$ on hotplate. After that the temperature was gradually increased to $90^{\circ} \mathrm{C}\left(10^{\circ} \mathrm{C} / \mathrm{min}\right)$ and after cooling down it was followed with dipping into mr-Dev 600 developer (Fig. 3e). The developing process was stopped by dipping the samples into isopropanol.

- Deposition of EpoClad layer as a cover protection layer by spin coating (Fig. 3f) was the last step. a)

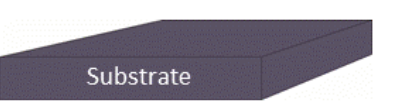

c)

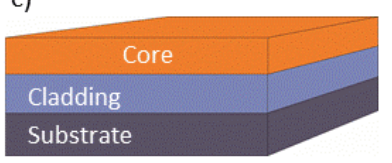

e)

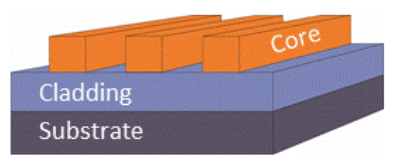

b)

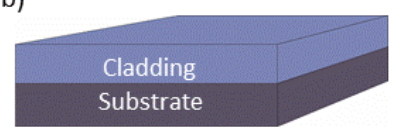

d)

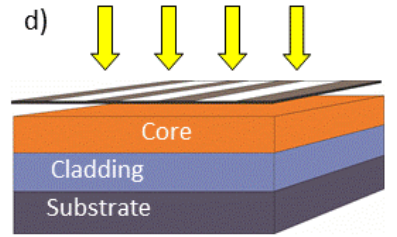

f)

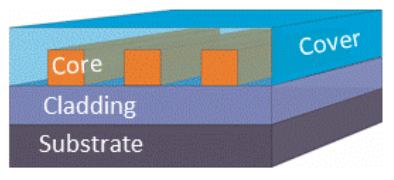

Fig. 3. Fabrication process for EpoCore optical planar waveguides a) substrate cleaning, b) deposition of EpoClad cladding layer, c) deposition of EpoCore waveguide layer, d) UV curing process, e) wet etching, f) deposition of EpoClad cover layer. 


\section{Measurements and Results}

The thicknesses of the fabricated polymer layers were measured by profile-meters Talystep Hommel Tester 1000. The experimentally found thickness of the cladding layer was around $20 \mu \mathrm{m}$ and that of the core waveguide layers varied from 20 up to $80 \mu \mathrm{m}$ depending on the rate of spinning of the coater during the deposition.

Properties of the ridge waveguides were checked using optical digital camera ARTCAMI which is equipped with optical head ZOOM Optics (Olympus Czech Group Ltd.). The camera was controlled by QUICKFOTO software. The measurement revealed that the ridge waveguides had good optical quality and dimension of the fabricated structure corresponded well with the size of the proposed waveguides. The images of the ridge waveguides are shown in Fig. 4 where Fig. 4 a shows top view image and Fig. $4 \mathrm{~b}$ shows the edge view.

Waveguiding properties of the planar waveguides were examined by dark mode spectroscopy using Metricon 2010 prism-coupler system [15] at five wavelengths 473, $632.8,964,1311$ and $1552 \mathrm{~nm}$. Index refraction of the planar waveguide can be determined by measuring of the critical angle of the incidence at the interface between the prism and the material in contact with the coupling prism. A typical example of the result in a form of mode spectra is given in Fig. 5.

Critical angles of incidence determine refractive indices of the waveguiding (EpoCore, $n_{\mathrm{f}}$ ) and cladding

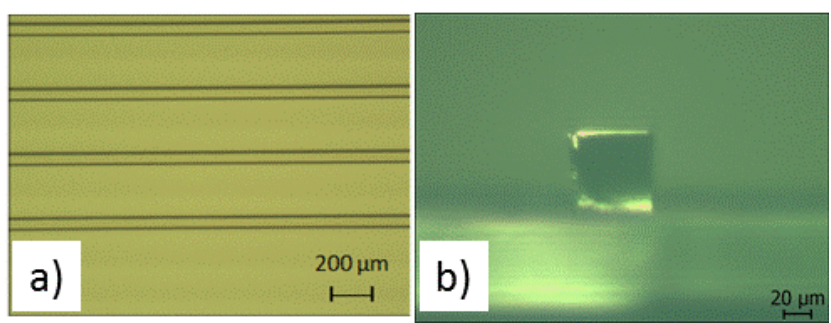

Fig. 4. Images of EpoClad/EpoCore ridge waveguides: a) top view, b) edge view.

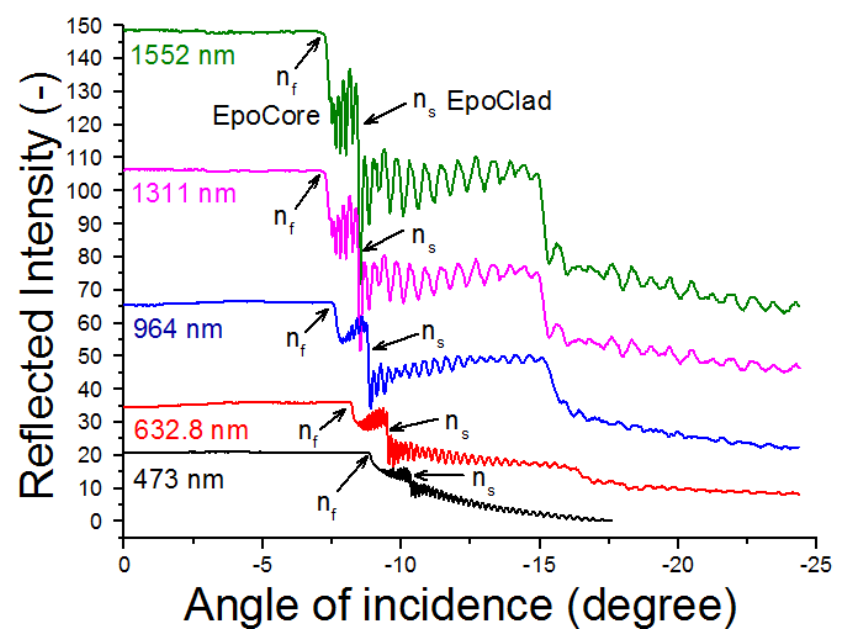

Fig. 5. Mode pattern of EpoCore/EpoClad planar waveguides.
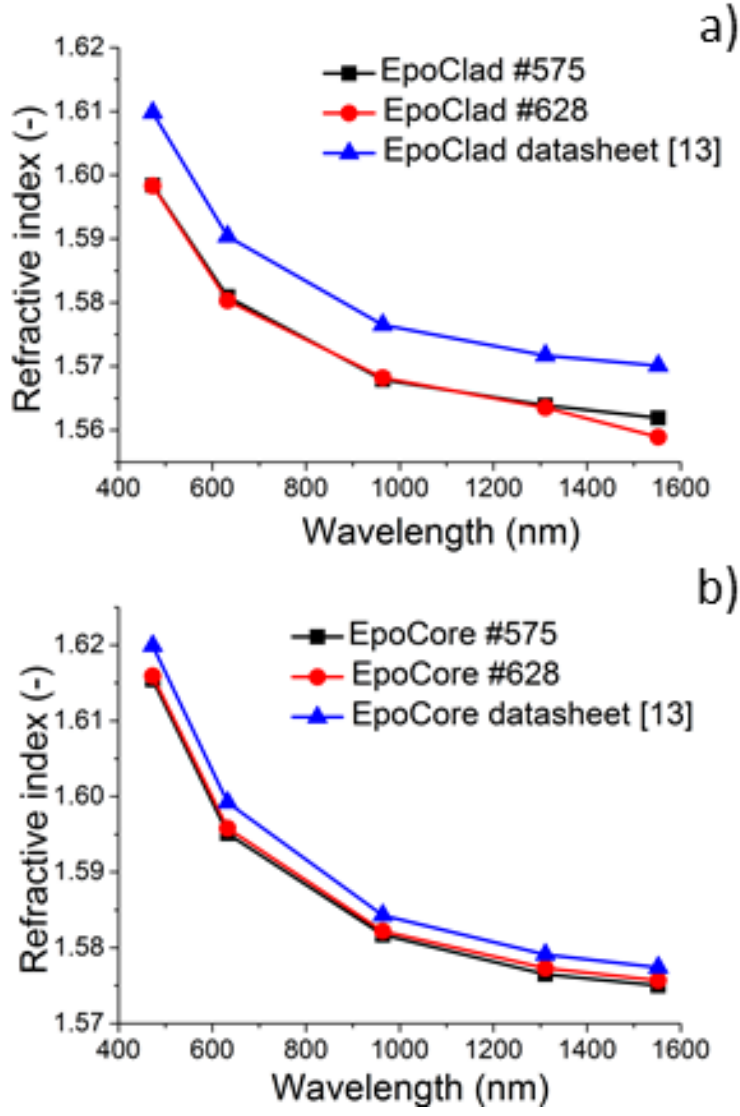

Fig. 6. Refractive indices measured by Metricon 2010 prismcoupler system and compared with datasheet values: a) EpoClad, b) EpoCore.

(EpoClad, $n_{\mathrm{s}}$ ) layers. For more details of such measurement see $[11,16]$.

Refractive indices for the EpoClad cladding and EpoCore core waveguides determined for the mode patterns are shown in Fig. 6.

In Fig. 6, measured refractive indices are compared to the data sheet [13] values for EpoClad and EpoCore epoxy polymer and it was found that value of refractive index for EpoClad were very similar to the tabular values. The values for the EpoCore were only marginally lower than those of the declared ones, in contrast with the measured refractive index values of EpoClad, that were found lower than tabular values. The reason for that was probably lower temperature of the final hardening of our samples, which was used to prevent deterioration of flexibility of our EpoClad foils.

Optical losses of our planar waveguides were measured by fiber probe technique. The principle of the measurement involves measurement of transmitted and scattering light intensity as a function of propagation distance along the waveguide $[12,17]$. The light is coupled into the planar waveguides through optical coupling prism and the outgoing scattered light intensity was detected by optical fiber connected to Si detector.

The results of optical loss measurements of the EpoCore planar waveguides are demonstrated in Fig. 7. 


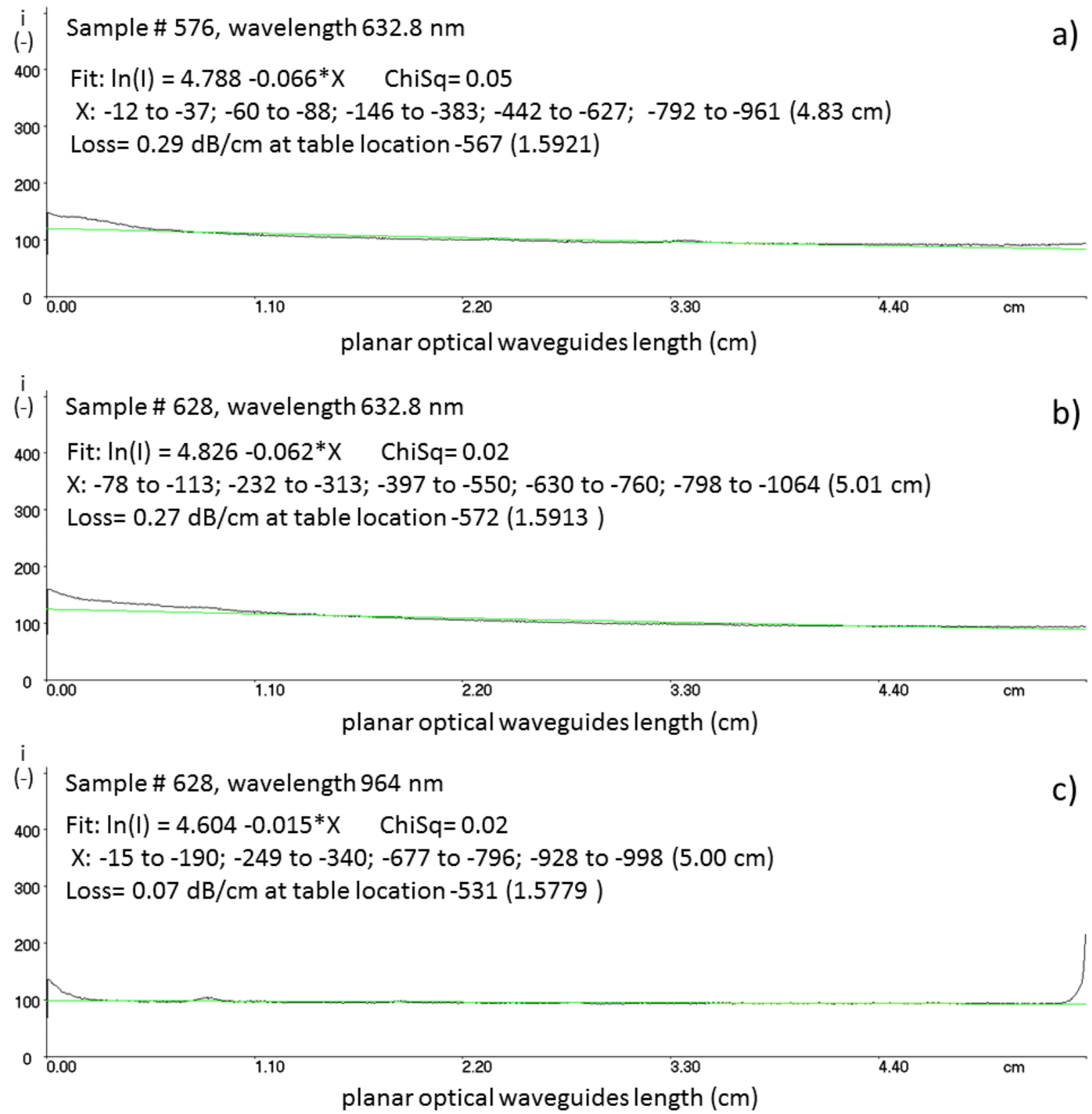

Fig. 7. Optical losses of the EpoCore/EpoClad planar waveguides on: a) Si substrate $(632.8 \mathrm{~nm})$, b) TOPAS substrate $(632.8 \mathrm{~nm})$, c) TOPAS substrate $(964 \mathrm{~nm})$.

Figure 7a shows the results for EpoCore waveguides deposited on silicon substrate and Figures $7 \mathrm{~b}$ and $\mathrm{c}$ give the results for the waveguides deposited on TOPAS substrate. Figures $7 \mathrm{a}$ and $\mathrm{b}$ demonstrate the measured values for the wavelength $632.8 \mathrm{~nm}$ while Figure 7c shows it for the wavelength $964 \mathrm{~nm}$. Our optical planar waveguides had optical losses lower than $0.3 \mathrm{~dB} \cdot \mathrm{cm}^{-1}$ with the best sample having optical losses as low as $0.27 \mathrm{~dB} \cdot \mathrm{cm}^{-1}$ at $632.8 \mathrm{~nm}$ and $0.07 \mathrm{~dB} \cdot \mathrm{cm}^{-1}$ at $964 \mathrm{~nm}$.

Optical loss measurements for ridge waveguides were done using the cut-back method. The principle of the method is shown in Fig. 8a while Figure $8 \mathrm{~b}$ shows a photo of the experimental set-up of the measurement. Optical losses were calculated using equation (1) [18]:

$$
\alpha=\frac{10 \cdot \log \frac{P_{1}[\mathrm{~W}]}{P_{2}[\mathrm{~W}]}}{\left(l_{1}-l_{2}\right)[\mathrm{cm}]}\left[\mathrm{dB} \cdot \mathrm{cm}^{-1}\right] .
$$

The measurements were done at: $650 \mathrm{~nm}$ (laser Safibra OFLS-5-FP-650), $850 \mathrm{~nm}$ (laser Safibra OFLS-6- LD-850) and $1310 \mathrm{~nm}$ (laser Safibra OFLS-6CH, SLED-1310). The output lights were measured by optical powermeter Thorlabs PM200 with Si detector S151C (measurements for wavelength 650 and $850 \mathrm{~nm}$ ) and InGaAs detector S155C (measurements for wavelength $1310 \mathrm{~nm}$ ). The accuracy of the measurement set-up is estimated to be $\pm 5 \%$. 

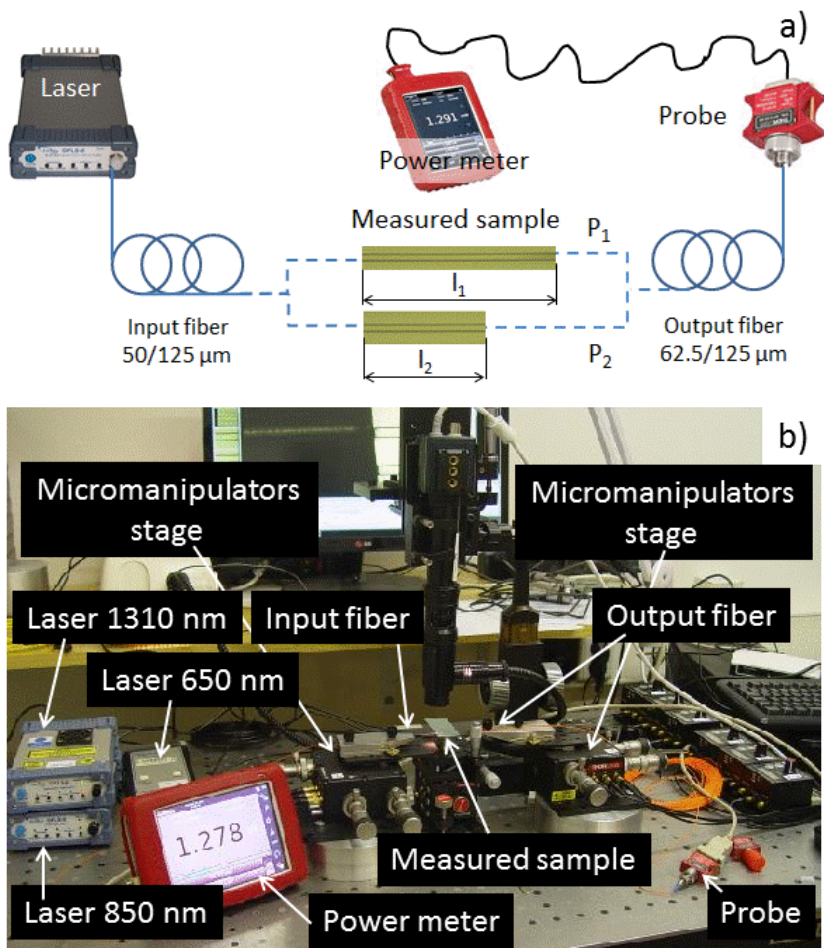

Fig. 8. Principle for insertion optical loss measurement: a) schematic view of the setup, b) image of the setup.

The measurement started with determination of the optical power $\left(P_{1}\right)$ emitted from the source and passing through the whole length $l_{1}$ of the ridge waveguide and proceeding through to the detector via output fiber waveguides. $P_{2}$ is the output optical power obtained after breaking the waveguide, where $l_{2}$ is the length of the broken part of the optical waveguide.

Detailed image of the ridge waveguide transmitting optical light $650 \mathrm{~nm}$ for optical loss measurements using the cut-back method is shown in Fig. 9.

Our fabricated optical channel waveguides had insertion optical losses lower than $0.60 \mathrm{~dB} \cdot \mathrm{cm}^{-1}$. The average value of the insertion optical losses were $0.36 \mathrm{~dB} \cdot \mathrm{cm}^{-1}$ at $650 \mathrm{~nm}, 0.32 \mathrm{~dB} \cdot \mathrm{cm}^{-1}$ at $850 \mathrm{~nm}$ and $0.53 \mathrm{~dB} \cdot \mathrm{cm}^{-1}$ at $1310 \mathrm{~nm}$. The best sample had optical losses $0.27 \mathrm{~dB} \cdot \mathrm{cm}^{-1}$ at $650 \mathrm{~nm}, 0.16 \mathrm{~dB} \mathrm{~cm}^{-1}$ at $850 \mathrm{~nm}$ and $0.30 \mathrm{~dB} \cdot \mathrm{cm}^{-1}$ at $1310 \mathrm{~nm}$

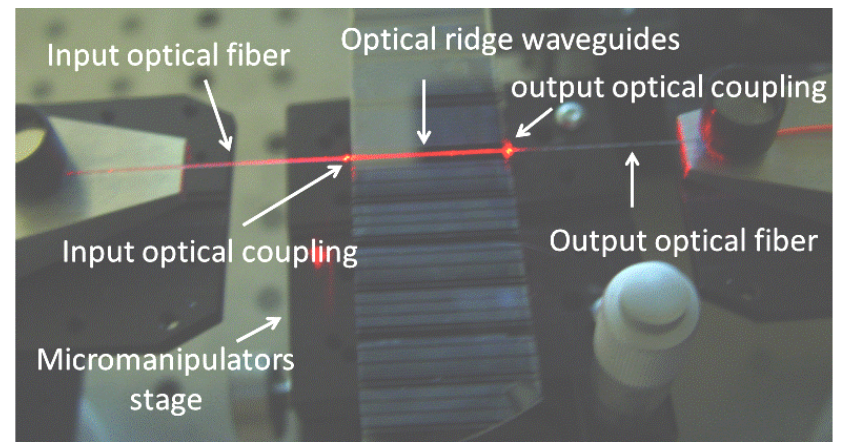

Fig. 9. Detailed image of the ridge waveguide transmitting optical light $650 \mathrm{~nm}$ for optical loss measurements using the cut-back method.

\section{Conclusion}

We report about properties of EpoClad/EpoCore polymer ridge waveguides fabricated on silicon and TOPAS $8007 \times 4$ substrate. Ridge waveguides were deposited by using spin coating and photolithography process.

Optical waveguiding properties of our planar waveguides samples were characterized by Metricon 2010 prism-coupler system for five wavelengths $(473,633,964$, 1311 and $1552 \mathrm{~nm}$ ) and optical losses were measured by collecting the scattered light using fiber scanning along the waveguide read by the $\mathrm{Si}$ photodetector at 632.8 and $964 \mathrm{~nm}$. The samples had optical losses less than $0.5 \mathrm{~dB} \cdot \mathrm{cm}^{-1}$ and the best sample has optical losses around $0.27 \mathrm{~dB} \cdot \mathrm{cm}^{-1}$ at $632.8 \mathrm{~nm}$ and $0.07 \mathrm{~dB} \cdot \mathrm{cm}^{-1}$ at $964 \mathrm{~nm}$. Insertion losses of the ridge waveguides were measured by cut-back method and the samples had optical losses lower than $0.6 \mathrm{~dB} \cdot \mathrm{cm}^{-1}$. The best samples have optical losses $0.27 \mathrm{~dB} \cdot \mathrm{cm}^{-1}$ at $650 \mathrm{~nm}, 0.16 \mathrm{~dB} \cdot \mathrm{cm}^{-1}$ at $850 \mathrm{~nm}$ and $0.30 \mathrm{~dB} \cdot \mathrm{cm}^{-1}$ at $1310 \mathrm{~nm}$.

\section{Acknowledgments}

The authors thank Topas Advanced Polymers company for providing TOPAS $8007 \mathrm{X} 4$ foils and Mr. M. Kucera from Masaryk University, Dept. of Condensed Matter Physics for technical support. This work was supported by the Epsilon Programme of the Technology Agency of the Czech Republic, project no. TH01020276, and by the CTU grant no. SGS17/188/OHK3/3T/13.

\section{References}

[1] BAMIEDAKIS, N., CHEN, J., PENTY, R.V., WHITE I. H. Bandwidth studies on multimode polymer waveguides for $25 \mathrm{~Gb} / \mathrm{s}$ optical interconnects. IEEE Photonics Technology Letters, 2014, vol. 26 , no. 20 , p. 2004-2007. DOI 10.1109/LPT.2014.2342881

[2] Bosman, E., Van STEENBERGE, G., MILENKOV, I., PANAJOTOV, K., THIENPONT, H., BAUWELINCK, J., Van DAELE, P. Fully flexible optoelectronic foil. IEEE Journal on Selected Topics in Quantum Electronics, 2010, vol. 16, no. 5, p. 1355-1362. DOI 10.1109/JSTQE.2009.2039466

[3] DANGEL, R., BERGER, C., BEYELER, R., DELLMANN, L., GMUR, M., HAMELIN, R., HORST, F., LAMPRECHT, T., MORF, T., OGGIONI, S., SPREAFICO, M., OFFREIN, B.J. Polymer-waveguide-based board-level optical interconnect technology for datacom applications. IEEE Transactions on Advanced Packaging, 2008, vol. 31, no. 4, p. 759-767. DOI: 10.1109/TADVP.2008.2005996

[4] CHOI, C., LIN, L., LIU, Y., CHOI, J., WANG, L., HAAS, D., MAGERA, J., CHEN, R.T. Flexible optical waveguide film fabrications and optoelectronic devices integration for fully embedded board-level optical interconnects. Journal of Lightwave Technology, 2004, vol. 22, no. 9, p. 2168-2176. DOI: 10.1109/JLT.2004.833815 
[5] BRUCK, R., MUEllner, P., KATAeVA, N., KOECK, A., TRASSL, S., RINNERBAUER, V., SCHMIDEGG, K., HAINBERGER, R. Flexible thin-film polymer waveguides fabricated in an industrial roll-to-roll process. Applied Optics, 2013 , vol. 52 , no. 19 , p. $4510-4514$. DOI: 10.1364/AO.52.004510

[6] HWANG, S.H., LEE, W.J., KIM, M.J., JUNG, E.J., KIM, G.W., AN, J.B., JUNG, K.Y., CHA, K.S., RHO, B.S. Ultra-thin and lowpower optical interconnect module based on a flexible optical printed circuit board. Optical Engineering, 2012, vol. 51, no. 7, Article Number: 075402. DOI: 10.1117/1.OE.51.7.075402

[7] IMMONEM, M., WU, J., YAN, H.J., ZHU, L.X., CHEN, P., RAPALA-VIRTANEN, T. Long distance optical printed circuit board for $10 \mathrm{Gbps}$ optical interconnection. Proceedings of SPIE, 2012, vol. 8555, Article Number: UNSP 85551M. DOI: $10.1117 / 12.999969$

[8] BAMIEDAKIS, N., CHEN, J., WESTBERGH, P., GUSTAVSSON, J. S., LARSSON, A., PENTY, R. V., WHITE, I. H. 40 Gb/s data transmission over a 1-m-long multimode polymer spiral waveguide for board-level optical interconnects. Journal of Lightwave Technology, 2015, vol. 33, p. 882-888. DOI: 10.1109/JLT.2014.2371491

[9] KOBAYASHI, J., YAGI, S., HATAKEYAMA, Y., KAWAKAMI, N. Low loss polymer optical waveguide replicated from flexible film stamp made of polymeric material. Japanese Journal of Applied Physics, 2013, vol. 52, Article Number: UNSP 072501. DOI: 10.7567/JJAP.52.072501

[10] PRAJZLER, V., NEKVINDOVÁ, P., HYPŠ, P., LYUTAKOV, O., JERABEK, V. Flexible polymer planar optical waveguides. Radioengineering, 2014, vol. 23, no. 3, p. 776-782. ISSN: 1210-2512

[11] PRAJZLER, V., NEKVINDOVÁ, P., HYPŠ, P., JERABEK, V. Properties of the optical planar polymer waveguides deposited on printed circuit boards. Radioengineering, 2015, vol. 24, no. 2, p. 442-448. DOI: $10.13164 / \mathrm{re} .2015 .0442$

[12] PRAJZLER, V., NEKVINDOVÁ, P., HYPŠ, P., JERABEK, V. Optical properties of polymer planar waveguides deposited on flexible foils. Journal of Optoelectronics and Advanced Materials, 2015, vol. 17, no. 11-12, p. 1597-1602.

[13] Micro resist technology GmbH: Datasheet. Available at: http://www.microresist.de

[14] TOPAS Advanced Polymers: Datasheet. Available at: http://www.topas.com/tech-center

[15] web Metricon Corporation. Available at: www.metricon.com

[16] ULRICH, R., TORGE, R. Measurement of thin film parameters with a prism coupler. Applied Optics, 1973, vol. 12, no. 12, p. 2901-2908. DOI: 10.1364/AO.12.002901

[17] NOURSHARGH, N., STARR, E. M., FOX, N. I., JONES, S. G. Simple technique for measuring attenuation of integrated optical waveguides. Electronics Letters, 1985, vol. 21, no. 18, p. 818-820. DOI: 10.1049/el:19850577

[18] ZIEMANN, O., KRAUSER, J., ZAMZOV, P. E., DAUM, W. POF Handbook, Optical Short Range Transmission Systems. $2^{\text {nd }}$ ed. Berlin (Germany): Springer-Verlag Berlin Heidelberg, 2008. ISBN 978-3-540-76628-5

\section{About the Authors ...}

Václav PRAJZLER was born in 1976 in Prague, Czech Republic. In 2001 he graduated from the Dept. of Microelectronics, Faculty of Electrical Engineering, Czech Technical University in Prague. In 2007 he obtained the Ph.D. degree from the same university. Since 2014 he has been an Associate Professor of Electronics with the Department of Microelectronic, Czech Technical University in Prague. His current research is focused on design, fabrication and investigation of properties of photonics structures.

Miloš NERUDA was born in 1975. His bachelor program was reached at the Department of Microelectronics at CTU in Prague in 2012 and his bachelor thesis was focused on the design, fabrication and investigated properties of multimode polymer planar optical power splitters. His current research is focused to design photonics structures.

Pavla NEKVINDOVÁ was born in 1972 in Kolín, Czech Republic. She graduated from the Institute of Chemical Technology, Prague (ICTP) in 1999. Now she is an Assistant Professor at the ICTP giving lectures on general and inorganic chemistry. She has worked there continuously in materials chemistry research. She has a long-term experience with fabrication and characterization of optical waveguiding structures in single-crystalline and glass materials.

Petr MIKULÍK was born in 1969 in Brno, Czech Republic. In 1992 he graduated from the Masaryk University, Brno, Czech Republic in Solid State Physics. In 1997 he obtained the Ph.D. degree under double leadership from the Masaryk University and from Université Joseph Fourier, Grenoble, France. Since 2009 he has been an Associate Professor Masaryk University Brno and now he is working at the Department of Condensed Matter Physics from the same university. 